\title{
PENGARUH MUTU BIJI COKLAT KERING PADA PROSES PENGOLAHAN PRODUK AWETAN COKLAT
}

\author{
Oleh : \\ Nami Lestari ${ }^{11}$
}

\begin{abstract}
ABSTRATC
This research has conducted to find out the effects of the cocoa beans quality on chocolate manufacture to produce the chocolate mass, chocolate butter and cocoa powder. Parameter evaluated of the cocoa beans quality (SNI 01-23232002) were moisture, insects, fungi, foreigh matters, and shell content. Parameter analysis of the chocolate mass were colour, flavor, moisture, butter and $\mathrm{pH}$. The analysis of the cocoa butter were colour. flavor and free fatty acid (FFA) content. The analysis of cocoa powder were colour, flavor, butter content, $\mathrm{pH}$ and total plate count. The quality of cocoa beans coming from 6 (six) regencies was analyzed and tehe the best two (from Kutai Timur and Samarinda) of them were chosen for further process to make chocolate mass. After that cocoa butter and powder produced. All the quality of cocoa beans, chocolate mass, cocoa butter and cocoa powder were analyzed based on appropriate National Standard of Indonesia (SNI). The main quality parameters, influencing the products were moeisture and fat content while the key step of process to meet the standard were the fermentation, roasting and pressing.
\end{abstract}

Keywords : the cocoa beans quality, the chocolate mass, the cocoa butter and cocoa powder

\section{PENDAHULUAN}

Dotensi tanaman coklat di Kalimantan Timur cukup besar yaitu luas tanaman tahun 2006 sebesar 36.719 ha, dengan produksi sebesar 34.546 ton (Dinas Perkebunan Prop. Kaltim, 2006). Sebagian besar areal kebun tersebut berasal dari kebun rakyat. Saat ini sebagian besar biji coklat dijual sebagai bahan mentah yang nilai ekonominya lebih rendah dibanding produk olahannya.

Untuk dapat meningkatkan nilai tambah dari hasil produksi coklat kepada petani. perlu dicarikan teknologi sederhana pengolahan coklat sehingga petani dapat melakukan diversifikasi produk olahan coklat. Produk olahan biji coklat yang memiliki nilai ekonomi tinggi dan banyak diperlukan oleh industri pangan dan farmasi adalah lemak coklat, disamping kakao massa dan bubuk coklat.

Salah satu kendala dalam pengembangan industri coklat skala UKM adalah mutu biji coklat kering yang dihasilkan belum baik dan kurang seragam mutunya. Disamping itu kurangnya penguasaan teknologi proses pengolahan biji coklat kering dan produk olahannya. Tujuan penelitian ini adalah mengetahui pengaruh mutu biji coklat kering

") Peneitit Eanstand inoustri Samiarinda 
pada proses pengolahan produk awetan coklat, seperti kakao massa, lemak coklat dan bubuk coklat.

\section{BAHAN DAN METODA}

Bahan yang digunakan dalam penelitian ini adalah biji coklat kering yang diperoleh dari beberapa daerah TK II di Kalimantan Timur, dan bahan untuk analisis. Sedangkan alat-alat yang digunakan adalah alat pengupas kulit, alat pres lemak, penangas, alat penggiling, timbangan, dan alat-alat untuk analisis.

Metoda penelitian yang dilakukan terdiri dari 2 tahap, yaitu :

1. Penelitian Pendahuluan

Penelitian Pendahuluan dilakukan dengan cara pengambilan sampel biji coklat kering dari 6 kabupaten/kota di Kalimantan Timur yang mempunyai potensi tanaman coklat cukup besar yaitu Bulungan, Kutai Timur, Kutai Kertanegara, Samarinda, Berau dan Penajam. Pengambilan sampel dilakukan 3 kali ulangan. Sampel tersebut dianalisis sesuai Syarat Mutu Biji Coklat Kering

(SNI-01-2323-2002).

2. Penelitian Lanjutan

Penelitian lanjutan dilakukan untuk mengembangkan teknologi proses pengolahan biji coklat kering menjadi kakao massa, lemak coklat dan bubuk coklat. Diagram alir proses pengolahan coklat dapat dilihat pada Gambar 1.

Perlakuan dalam pengolahan biji coklat kering menjadi beberapa produk olahan coklat adalah jenis biji coklat kering dari 2 daerah di Kalimantan Timur dengan mutu biji coklat terpilih dari hasil analisis Penelitian Pendahuluan. Dari hasil analisis diperoleh biji coklat dengan mutu yang cukup baik adalah berasal dari Samarinda dan Kutai Timur.

\section{ANALISIS}

Analisis dilakukan meliputi analisis mutu biji coklat kering sesuai dengan SNI 01 2323-2002 (Biji Coklat Kering), analisis kakao massa meliputi parameter uji cita rasa (aroma, rasa dan warna) kadar air, kadar lemak dan pH sesuai dengan SNI 01-3749-1995 (Kakao Massa), dan analisis lemak coklat meliputi uji cita rasa (aroma, rasa dan warna), dan asam lemak bebas sesuai dengan SNI 01-3748-1995. Sedangkan analisis bubuk coklat meliputi uji cita rasa (aroma, rasa dan warna), kadar air, kadar lemak dan pH sesuai dengan SNI 01-3747-1995 (Bubuk Coklat).

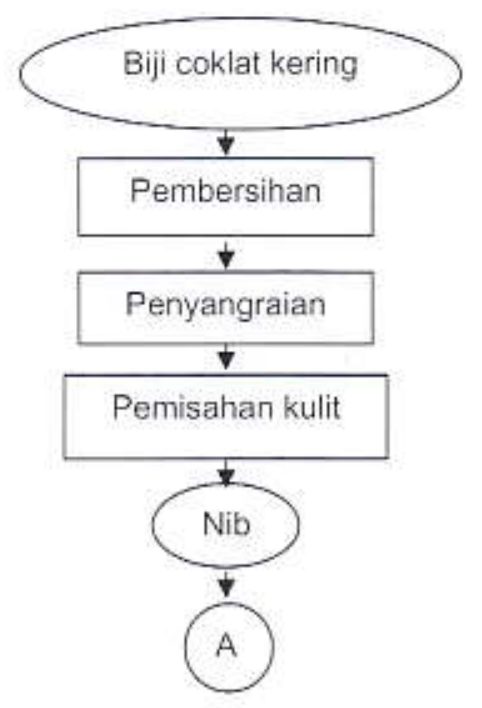




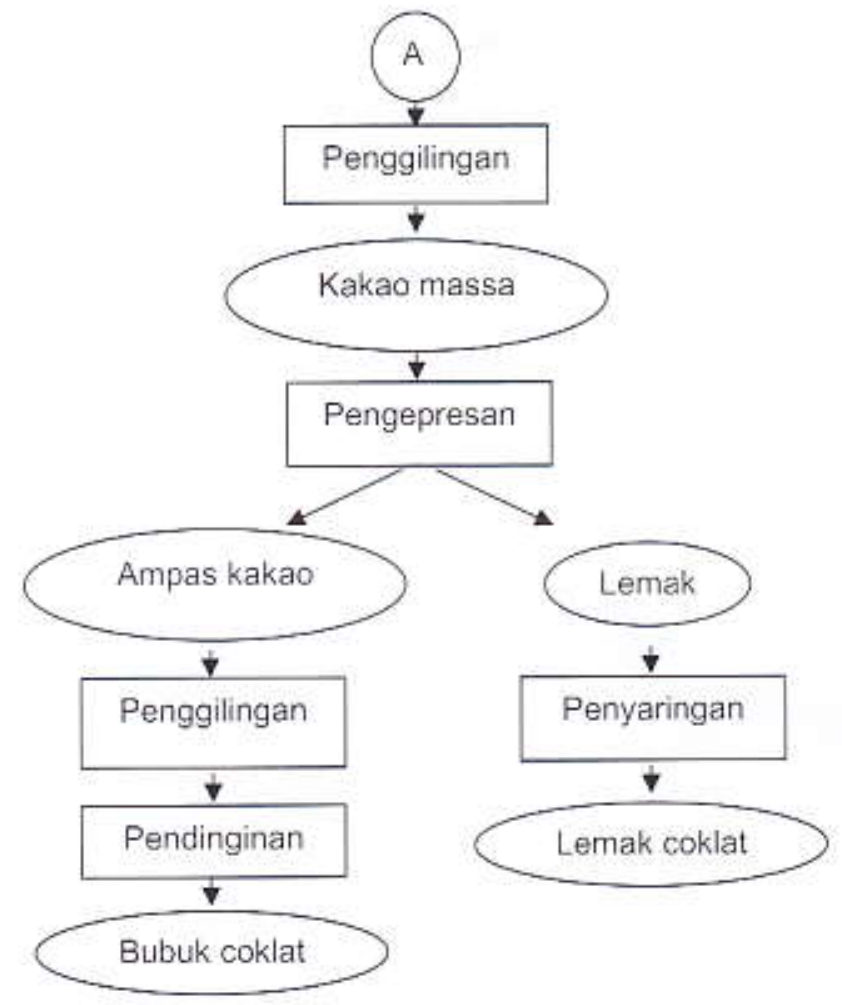

Gambar 1. Pengolahan biji coklat kering menjadi kakao massa, lemak coklat dan bubuk coklat (sumber : BBIHP 2000).

\section{HASIL DAN PEMBAHASAN}

\section{A. MUTU BIJI COKLAT}

Tabel 1. Hasil analisis mutu biji coklat kering dari beberapa daerah di Kalimantan Timur sesuai SNI 01-2323-2002

\begin{tabular}{|c|c|c|c|c|c|c|c|c|}
\hline No & $\begin{array}{c}\text { Parameter } \\
\text { Uji }\end{array}$ & Satuan & Bulungan & $\begin{array}{c}\text { Kutai } \\
\text { Timur }\end{array}$ & Samarinda & $\begin{array}{c}\text { Kutai } \\
\text { Kartanegara }\end{array}$ & Berau & Penajam \\
\hline 1. & $\begin{array}{c}\text { Serangga } \\
\text { hidup }\end{array}$ & - & tak ada & $\begin{array}{c}\text { Tak } \\
\text { ada }\end{array}$ & tak ada & Tak ada & $\begin{array}{c}\text { Tak } \\
\text { ada }\end{array}$ & Tak ada \\
\hline 2. & $\begin{array}{c}\text { Kadar air } \\
\text { Bji berbau } \\
\text { asap dan } \\
\text { atau } \\
\text { abnormal } \\
\text { dan atau } \\
\text { berbau } \\
\text { asing }\end{array}$ & - & Tak ada & $\begin{array}{c}\text { Tak } \\
\text { ada }\end{array}$ & Tak ada & Tak ada & $\begin{array}{c}\text { Tak } \\
\text { ada }\end{array}$ & Tak ada \\
\hline 4. & $\begin{array}{c}\text { Kadar Biji } \\
\text { Pecah }\end{array}$ & $\%$ bib & 1,32 & 0 & 1,06 & 0,64 & 11,22 & 9,17 \\
\hline 5. & $\begin{array}{c}\text { Kadar } \\
\text { Kotoran }\end{array}$ & $\%$ bib & 1,55 & 0,46 & 0,47 & 2,34 & 2,29 & 1,87 \\
\hline 6. & $\begin{array}{c}\text { Kadar } \\
\text { Benda Asing }\end{array}$ & $\%$ bit & 0,00 & 0,00 & 0,00 & 0,00 & 0,00 & 0,00 \\
\hline
\end{tabular}




\begin{tabular}{|c|c|c|c|c|c|c|c|c|}
\hline 7. & $\begin{array}{c}\text { Kotoran } \\
\text { Mamalia }\end{array}$ & $\%$ piti & 0,00 & 0,00 & 0,00 & 0,00 & 0,00 & 0,00 \\
\hline 8. & $\begin{array}{c}\text { Jumlah Biji } \\
\text { per } 100 \\
\text { gram }\end{array}$ & 95 & 135 & 125 & 145 & 121 & 149 \\
\hline 9. & $\begin{array}{c}\text { Kadar Biji } \\
\text { Berkapang }\end{array}$ & Biji/Biji & 3,00 & 3,00 & 6,00 & 4,00 & 3,00 & 3,00 \\
\hline 10. & $\begin{array}{c}\text { Kadar Biji } \\
\text { Tidak } \\
\text { Terfermen- } \\
\text { tasi }\end{array}$ & Biji/Biji & 32,67 & 3,00 & 5,00 & 8,00 & 6,00 & 4,00 \\
\hline 11. & $\begin{array}{c}\text { Kadar Biji } \\
\text { Berserangga }\end{array}$ & Bij/Biji & 2,00 & 1,00 & 2,00 & 1,00 & 1,00 & 1,00 \\
\hline 12. & $\begin{array}{c}\text { Kadar Biji } \\
\text { Berkecam- } \\
\text { bah }\end{array}$ & Biji/Biji & 1,00 & 1,00 & 3,00 & 2,00 & 2,00 & 2,00 \\
\hline 13. & $\begin{array}{c}\text { Kadar } \\
\text { Lemak }\end{array}$ & $\%$ t.. & 45,3 & 47,4 & 48,69 & 41,29 & 46,55 & 46,7 \\
\hline
\end{tabular}

Dari hasil analisis tersebut, terlihat bahwa kadar air biji coklat kering yang dihasilkan petani di Kalimantan Timur berkisar antara 7,4 \% sampai 11,2\%. Standar mutu kadar air biji coklat kering berdasarkan SNI adalah maksimun 7,5\% sehingga sampel banyak yang belum memenuhi standar mutu. Pengolahan biji coklat kering yang dilakukan petani di daerah Kalimantan Timur sangat sederhana, yaitu buah coklat dipanen, dipecahkan diambil bijinya, difermentasi sederhana yaitu di peram dalam karung selama 1(satu) malam dan dikeringkan.

Menurut Suprapti (2001) pengolahan biji coklat yang menentukan mutu hasil akhir adalah tahap fermentasi dan pengeringannya. Pada tahap fermentasi akan terjadi perubahan-perubahan baik di luar maupun di dalam keping biji. Perubahan-perubahan di luar biji biasa dinamakan fermentasi eksternal, yaitu terjadi perubahan-perubahan pulp secara biokhemis, khemis dan fisis. Selanjutnya terjadi perubahan-perubahan secara internal, yaitu perubahan-perubahan dalam keping biji secara enzimatis yang berlarut ke tahap pengeringan.

Pada tahap pengeringan, akan mempengaruhi kadar air, dengan kadar air yang rendah, biji coklat akan lebih tahan atau awet dalam penyimpanan yaitu mengurangi tumbuhnya kapang, teksturnya akan lebih baik, serta akan memudahkan dalam proses penyangraian pada pengolahan menjadi produk-produk selanjutnya. Proses penyangraian biji coklat merupakan suatu tahap proses yamg sangat penting dalam pengembangan aroma dan cita rasa senyawa-senyawa yang terdapat dalam biji coklat (Suprapti, 2001).

Menurut Susanto (1994), faktor yang mempengaruhi aroma dan flavor coklat adalah fermentasi yang baik adalah dengan cara diperam dalam kotak berlubang dan bertingkat, dengan lama fermentasi selama $5-7$ hari, serta dilakukan pengadukan. Sedangkan pengeringan yang baik adalah kombinasi antara pengeringan dengan sinar matahari dan alat pengering buatan. Caranya adalah tahap pertama biji dijemur selama $14-16$ jam, lalu dikeringkan dengan alat pengering selama $34-44$ jam.

Pengeringan dihentikan bila kadar air sudah turun dari $60 \%$ menjadi $6 \%-7,5 \%$.Cara yang dapat digunakan untuk menentukan selesainya pengeringan adalah :

- Mengukur kadar air, yaitu sudah mencapai $6 \%-7,5 \%$

- Bila berat biji kering sudah menjadi ${ }^{1} / 3$ biji basah

- Biji yang cukup kering mudah patah dan rapuh

Dari analisis kadar biji pecah, kisarannya antara $0 \%$ sampai $1,92 \%$, memenuhi syarat (SNI maksimum $2 \%$ ), kadar kotoran, kisarannya antara 0,46\% sampai $2,29 \%$, memenuhi syarat (SNI maksimum $2,5 \%$ ). Kadar benda asing seluruhnya 0 . Kotoran mamalia seluruhnya 0 . Jumlah biji per 100 gram kisarannya antara 95 sampai 145 , sedangkan syarat mutu SNI, jumlah biji per 100 gram berbeda-beda tergantung jenis 
mutunya, yaitu kisarannya antara $85-120$, serta minimal 120. Kadar biji berkapang kisarannya antara 3,00 sampai 6,00 , syarat mutu SNI maksimum $4 \%$, jadi ada beberapa sampel yang tidak memenuhi syarat SNI.

Untuk analisis kadar biji tidak terfermentasi, kisarannya antara 4 biji/biji sampai 32,67 bijibiji, masih memenuhi syarat ( SNI maksimum 50 biji/biji). Kadar biji berserangga, kisarannya antara 1,0 bij/biji sampai 2,00 bij//biji, memenuhi syarat ( $S N$ I maksimal 2 biji/biji ), kadar biji berkecambah, kisarannya antara 1,00 biji/biji sampai 3 bijilbiji, memenuhi syarat ( $\mathrm{SNI}$ maksimal 3 bijibiji).

Dari hasil analisis kadar lemaknya, di dapat kadar lemak biji coklat kering dari 6 daerah tersebut berkisar antara $41,29 \%$ sampai $48,64 \%$. Kadar lemak biji coklat kering tidak disyaratkan pada standar SNI, namun kandungan lemak akan mempengaruhi mutu produk olahan coklat yang dihasilkan. Menurut Susanto (1994), kandungan lemak ini dipengaruhi oleh bahan tanaman, misalnya kultur lindak lebih tinggi dari kultur mulia. Disamping itu kandungan lemak juga dipengaruhi ukuran biji, yaitu biji dengan berat kurang dari 1 gram tiap biji, maka kadar lemaknya lebih rendah dari biji yang beratnya 1 gram atau lebih.

Biji yang bermutu baik mempunyai berat rata-rata 1,0 - 1,2 gram atau sekitar 83 100 biji tiap 100 gram. Ukuran biji ini dipengaruhi oleh bahan tanaman dan curah hujan pada waktu perkembangan buah, disamping mempengaruhi kadar lemak, ukuran biji ada kaitannya dengan pengolahan selanjutnya, yaitu biji yang ukurannya seragam akan mencapai derajat penyangraian yang seragam pula, serta biji yang kecil cenderung tersangrai lebih cepat (Susanto, 1994).

\section{B. PENGOLAHAN COKLAT}

Penelitian lanjutan yang dilakukan adalah proses pengolahan biji coklat menjadi produk kakao massa lemak coklat dan bubuk coklat. Tahapan proses pengolahan biji coklat adalah sebagai berikut :

\section{Pembersihan}

Pembersihan bertujuan untuk membersihkan biji coklat dari kotoran-kotoran seperti tanah, kerikil logam-logam daun kering dan lain-lain. Pembersihan dilakukan dengan pengayakan.

2. Penyangraian (roasting)

Penyangraian adalah tahap awal yang penting pada pembuatan produk olahan coklat, yaitu akan merubah cita rasa menjadi khas coklat yang diinginkan, merubah warna, tekstur dan lain-lain. Penyangraian dilakukan di wajan dengan suhu $<99^{\circ} \mathrm{C}$ dan waktu penyangraian sekitar 60 menit.

3. Pengupasan (Winnowing)

Tujuan pengupasan adalah untuk memisahkan kulit, lembaga dan keping biji. Alat yang digunakan adalah alat pengupas kulit sekaligus penghancur biji coklat (desheller tipe rotary cutter) menghasilkan nib. Rendemen nib sebesar $77,27 \%-83 \%$.

4. Penggilingan

Setelah diperoleh nib, selanjutnya dilakukan pemggilingan menjadi kakao massa dengan alt penggiling. Rendemen kakao massa dari nib sebesar $100 \%$.

5. Pengepresan Lemak

Pengepresan lemak bertujuan untuk mendapatkan lemak coklat dan bubuk coklat. Alat yang digunakan adalah alat pres nib kakao massa pasca sangrai tipe hidrolik. Rendemen lemak coklat sebesar $20-22 \%$ dan kadar lemak bubuk coklat sebesar $33,47 \%-38,85 \%$.

Hasil analisis produk-produk olahan coklat adalah :

a. Kakao Massa

Hasil analisis kakao massa dapat dilihat pada Tabel 2. 
Tabel 2. Hasil analisis kakao massa

\begin{tabular}{|c|c|c|c|}
\hline \multirow{2}{*}{ No } & \multirow{2}{*}{ Analisis } & \multicolumn{2}{|c|}{ Kakao Massa } \\
\cline { 3 - 4 } & & I & II \\
\hline 1. & Aroma & Normal & Normal \\
\hline 2. & Rasa & Normal & Normal \\
\hline 3. & Warna & Normal & 3,87 \\
\hline 4. & Kadar Air $(\%)$ & 4,58 & 46,7 \\
\hline 5. & Kadar Lemak $(\%)$ & 46,1 & 5,28 \\
\hline 6. & $\mathrm{pH}$ & 5,3 & \\
\hline
\end{tabular}

Keterangan : I = Biji coklat kering asal Samarinda

$\|$ = Biji coklat kering asal Kutai Timur

Proses yang mempengaruhi mutu kakao massa, terutama kadar airnya adalah proses penyangraian biji coklat sebelum dikupas dan digiling. Kadar air mempengaruhi keawetan kakao massa, semakin tinggi kadar airnya akan semakin mudah ditumbuhi jamur atau kapang. Untuk mendapatkan kadar air kakao massa yang cukup rendah agar jamur atau kapang sulit tumbuh, waktu dan derajat penyangraian harus terkontrol. Suhu penyangraian rendah, yaitu $<99^{\circ} \mathrm{C}$ dan waktu penyangraian 60 menit. Setelah penyangraian selesai, dengan segera biji dikeluarkan dari wajan dan didinginkan untuk mencegah biji hangus dengan disertai kerusakan warna dan flavor. Kadar air biji coklat asal Samarinda dan Kutai Timur cukup tinggi, jadi untuk mendapatkan kadar air kakao massa yang lebih rendah agar jamur atau kapang sulit tumbuh, proses penyangraian dilakukan lebih dari 60 menit.

Di samping proses penyangraian, faktor yang mempengaruhi kadar air kakao massa, adalah kadar air biji coklat sebelum disangrai, semakin tinggi kadar air biji coklat awal proses, akan semakin lama penyangraian dilakukan. Dari hasil analisis yang terlihat, kadar air kakao massa asal Samarinda lebih tinggi (4,58\%) dibandingkan kakao massa asal Kutai Timur $(3,87 \%)$. Hasil ini dipengaruhi kadar air biji coklat kering asal Samarinda yang lebih tinggi $(7,98 \%)$ dari biji coklat asal Kutai Timur $(7,14 \%)$.

Dari hasil analisa kadar lemak kakao massa terlihat cukup tinggi antara 46,1\% $46,7 \%$, namun masih dibawah standar SNI 01-3749-1995 (kakao massa), yaitu minimum $48 \%$. Kadar lemak tidak dipersyaratkan dalam SNI biji coklat kering, namun akan, mempengaruhi produk olahanya, seperti kakao massa disamping dipengaruhi juga oleh proses pengepresannya. $\mathrm{pH}$ kakao massa menunjukkan derajat keasaman, yang menentukan cita rasa dan aroma serta keawetan produk. Dari hasil analisis, $\mathrm{pH}$ kakao massa antara 5,28 sampai 5,3. Menurut Kniel (1999) dalam BBIHP (2000), pH kakao massa antara $5,2-5,8$.

\section{b. Lemak Coklat}

Hasil analisis lemak coklat dapat dilihat pada Tabel 3.

Tabel 3. Hasil analisis lemak coklat

\begin{tabular}{|c|c|c|c|}
\hline \multirow{2}{*}{ No. } & \multirow{2}{*}{ Analisis } & \multicolumn{2}{|c|}{ Hasil } \\
\hline & & I & II \\
\hline 1. & Aroma & $\begin{array}{c}\text { Normal, khas lemak } \\
\text { coklat }\end{array}$ & $\begin{array}{c}\text { Normal, khas lemak } \\
\text { coklat }\end{array}$ \\
\hline 2. & Rasa & $\begin{array}{c}\text { Normal, khas lemak } \\
\text { coklat }\end{array}$ & $\begin{array}{c}\text { Normal, khas lemak } \\
\text { coklat }\end{array}$ \\
\hline 3. & Warna & $\begin{array}{c}\text { Norma, khas lemak } \\
\text { coklat }\end{array}$ & $\begin{array}{c}\text { Normal, khas lemak } \\
\text { coklat }\end{array}$ \\
\hline 4. & Asam Lemak bebas & $1,42 \%$ & $1,12 \%$ \\
\hline
\end{tabular}

Keterangan $: 1$ = Biji coklat kering asal Samarinda

II = Biji coklat kering asal Kutai Timur 
Dari hasil tersebut terlihat bahwa asam lemak bebasnya memenuhi syarat SNI $01-$ $3748-1995$, yaitu besarnya di bawah $1,75 \%$. Aroma dan rasanya normal dan khas lemak coklat, warna lemak kuning, dalam suhu ruang lemak membeku, dan bila dipanaskan lemak coklat mencair.

Menurut BBIHP (2000), lemak coklat merupakan campuran dari beberapa trigliserida dan dapat mengkristal dalam berbagai bentuk ( polymerphie). Pada suhu $20^{\circ} \mathrm{C}$ berbentuk padat, sedangkan pada suhu di atas $35^{\circ} \mathrm{C}$ berbentuk cair dan berwarna kuning, kadar asam lemak bebasnya maksimum $1,5 \%$.

Kegunaan lemak coklat adalah untuk berbagai olahan coklat, seperti coklat batang, selai coklat, permen coklat dan lain-lain. Komposisi dasar coklat bervariasi, tapi tiga jenis formula yang sudah dikenal adalah coklat gelap terdiri dari kakao massa, lemak kakao, gula, lemak susu dan emulsifier. Coklat susu terdiri dari kakao massa, lemak susu, gula, susu bubuk, susu krim dan emulsifier. Sedangkan coklat putih bahannya sama seperti coklat susu tapi tanpa menggunakan kakao massa (BBHIP, 2000).

c. Bubuk coklat

Hasil analisis bubuk coklat dapat dilihat pada Tabel 4 .

Tabel 4. Hasil analisis bubuk coklat

\begin{tabular}{|c|c|c|c|}
\hline \multirow{2}{*}{ No. } & \multirow{2}{*}{ Analisis } & \multicolumn{2}{|c|}{ Hasil } \\
\cline { 3 - 4 } & & I & II \\
\hline 1. & Aroma & Normal & Normal \\
\hline 2. & Rasa & Normal & Normal \\
\hline 3. & Warna & Normal & Normal \\
\hline 4. & Kadar Air $(\%)$ & 3,78 & 2,46 \\
\hline 5. & Kadar Lemak $(\%)$ & 38.85 & 33,47 \\
\hline 6. & $\mathrm{pH}$ & 5,08 & 5.36 \\
\hline 7. & Angka Lempeng Total (Koloni/gram) & $1.9 \times 10^{3}$ & $1,3 \times 10^{3}$ \\
\hline
\end{tabular}

Keterangan $: 1=$ Biji coklat kering asa/ Samarinda

$\|$ = Biji coklat kering asal Kutai Timur

Karakteristik yang penting dari bubuk coklat adalah kadar air, kadar lemak, $\mathrm{pH}$, cita rasa ( aroma, rasa dan warna) serta mikrobiologis ( angka lempeng total) Ranken (1989) dalam Suprapti (2006). Dari hasil analisis tersebut terlihat bahwa kadar air bubuk coklat memenuhi syarat SNI 01-3747-1995, yaitu di bawah 5\%. Kadar air bubuk coklat dipengaruhi oleh penyangraian biji coklat, semakin optimal proses penyangraian biji coklat, kadar air biji coklat dan kadar air bubuk coklat akan lebih awet dan teksturnya lebih baik. yaitu tidak menggumpal.

Untuk kadar lemaknya, pada bubuk coklat hasil percobaan masih tinggi dan belum memenuhi syarat SNI yaitu di atas $8 \%$. Hasil ini menunjukkan bahwa alat proses yang digunakan tidak efektif, yaitu pada saat pengepresan, lemak tidak terlalu banyak yang keluar, sehingga masih banyak tertinggal pada bubuk coklat.

Dengan masih tingginya kadar lemak, pada saat penggilingan bubuk coklat akan lebih sulit,dan teksturnya agak menggumpal. Untuk mendapatkan hasil pengepresan lemak yang optimal, diperlukan alat pres hidrolik yang lebih baik lagi.

Dari analisis $\mathrm{pH}$, terlihat bahwa $\mathrm{pH}$ bubuk coklat memenuhi syarat SNI yaitu di atas $4,7 \%$. Hal ini menunjukkan bahwa bubuk coklat tidak terlalu asam, dengan tingginya $\mathrm{pH}$ diharapkan akan mengurangi keasaman dan kadar gulanya akan tinggi ( $\mathrm{BBHIP}$. 2000).

Biji coklat kering sebagai bahan baku untuk bubuk coklat harus memenuhi syarat mutu ( fisik dan kimiawi) dan harus diawasi secara ketat karena menyangkut cita rasa dan keamanan produk bagi konsumen (Mulato, 2005). Dari segi rasa dan aroma, bubuk coklat akan sangat baik jika biji coklat telah difermentasi. Dari segi kesehatan atau 
keamanan produk, biji coklat kering harus bebas jamur karena kontaminasi jamur akan menyebabkan rasa tengik, aroma apek dan produk tidak awet ( Surapti, 2006)

Dari hasil analisa biji coklat kering ( Tabel 1 ) terlihat kadar biji berkapang masih tinggi, yaitu antara $3-6$ biji/biji. Sedangkan syarat mutu SNI 01-2323-2002, kadar biji berkapang maksimum 2 bijilbiji. Untuk mengurangi jumlah kapang pada produk olahannya, seperti bubuk coklat, waktu penyangraian harus lebih lama.

Untuk segi efisiensi produksi, biji coklat dengan ukuran seragam akan mudah diolah dan mutu produk juga seragam. Ukuran biji yang seragam bila disangrai akan menghasilkan biji dengan kematangan yang seragam, sehingga mutu produk juga seragam ( Surapti, 2000). Kadar air yang tinggi juga akan menyebabkan waktu sangrai lebih lama. Adanya benda asing keras menyebabkan kerusakan alat dan berpengaruh negatif terhadap kualitas produk olahan coklat ( Mulato ( 2004 ) dalam Suprapti ( 2006 )).

\section{KESIMPULAN}

1. Berdasarkan pengujian mutu biji coklat kering dari 6 daerah TK II di Kalimantan Timur sesuai SNI 01-2323-2002, didapat biji coklat kering yang memenuhi syarat mutu adaiah yang berasal dari Kutai Timur.

2. Pengolahan biji coklat kering menjadi kakao massa, lemak coklat dan bubuk coklat menggunakan alat pres hidrolik menghasilkan rendemen lemak coklat sebesar $20 \%$ sampai $22 \%$, dan kadar lemak pada bubuk antara $33,47 \%$ sampai $38,85 \%$. Dengan tingginya kadar lemak pada bubuk coklat, penggunaan alat pres hidrolik belum efektif.

3. Faktor yang mempengaruhi mutu produk olahan coklat adalah mutu biji coklat kering seperti kadar air, serta proses pengolahan seperti penyangraian dan pengepresan biji coklat.

\section{SARAN}

1. Untuk mendapatkan lemak coklat yang lebih banyak dan mengurangi kandungan lemak pada bubuk coklat, diperlukan alat pres yang lebih efektif.

2. Perlu kerjasama dengan instansi terkait untuk mensosialisasikan penanganan biji coklat yang baik serta proses pengolahannya.

\section{DAFTAR PUSTAKA}

BBHIP. 2000. Pengembangan Produk Olahan Coklat Skala Kecil. Balai Besar Industri Hasil Pertanian Bogor.

BSN. 1995. Standar Nasional Indonesia (SNI) 01-3747-1995 Bubuk Coklat. Badan Standardisasi Nasional. Jakarta.

BSN. 1995. Standar Nasional Indonesia (SNI) 01-3748-1995 Lemak Coklat. Badan Standardisasi Nasional. Jakarta.

BSN. 1995. Standar Nasional Indonesia (SNI) 01-3749-1995 Kakao Massa. Badan Standardisasi Nasional. Jakarta.

BSN. 2002. Standar Nasional Indonesia (SNI) 01-2323-2002 Biji Coklat Kering. Badan Standardisasi Nasional. Jakarta.

Dinas Perkebunan. 2006. Potensi Tanaman Perkebunan Di Daerah TK I Kalimantan Timur. Dinas Perkebunan TK I Prop Kaltim. Samarinda. 
Ketaren. 1986. Pengantar Teknologi Minyak dan Lemak Pangan. Penerbit Universitas Indonesia ( UI Press). Jakarta.

Mulato, Sri. 2005. Pengolahan Produk Primer dan Sekunder Kakao. Pusat Penelitian Kopi dan Kakao Indonesia. Jember.

Nasution, Z. 1985. Pengolahan Coklat. Agro Industri Press. Bogor.

Pasullean, B. 2000. Pengolahan Kakao, Kendi dan Coklat Batangan Serta Maises. Balai Industri Ujung Pandang. Ujung Pandang.

Suprapti. 2000. Pemisahan Lemak Kakao dengan Menggunakan Metode Floating Untuk Pembuatan Coklat Bubuk Skala Industri Kecil. Balai Industri Ujung Pandang. Ujung Pandang.

Suprapti. 2006. Pengaruh Alkalisasi Bungkil Kakao Terhadap Mutu dan Cita Rasa Bubuk Coklat. Jurnal industri Hasil Perkebunan Vol. 34 No 2, Desember 2006. Balai Besar Industri Hasil Perkebunan. Makassar.

Susanto, Fx. 1994. Tanaman Kakao, Budidaya dan Pengolahan Hasil. Penerbit Kanisius. Yogyakarta. 